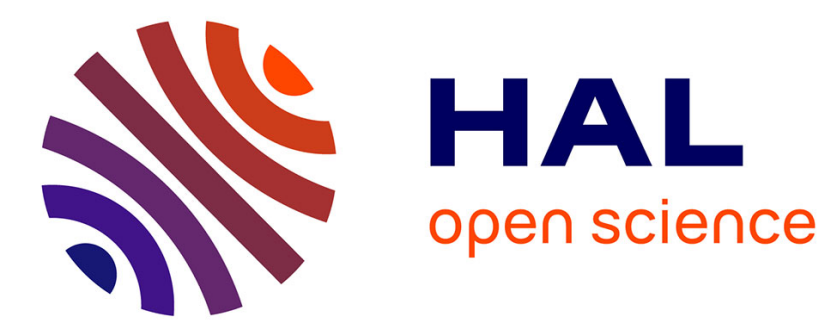

\title{
Charge density wave transport in irradiated orthorhombic TaS3
}

H. Mutka, S. Bouffard, G. Mihály, L. Mihály

\section{To cite this version:}

H. Mutka, S. Bouffard, G. Mihály, L. Mihály. Charge density wave transport in irradiated orthorhombic TaS3. Journal de Physique Lettres, 1984, 45 (3), pp.113-119. 10.1051/jphyslet:01984004503011300 . jpa-00232316

\section{HAL Id: jpa-00232316 https://hal.science/jpa-00232316}

Submitted on 1 Jan 1984

HAL is a multi-disciplinary open access archive for the deposit and dissemination of scientific research documents, whether they are published or not. The documents may come from teaching and research institutions in France or abroad, or from public or private research centers.
L'archive ouverte pluridisciplinaire HAL, est destinée au dépôt et à la diffusion de documents scientifiques de niveau recherche, publiés ou non, émanant des établissements d'enseignement et de recherche français ou étrangers, des laboratoires publics ou privés. 
Classification

Physics Abstracts

$61.80 \mathrm{~F}-72.15 \mathrm{~N}$

\title{
Charge density wave transport in irradiated orthorhombic $\mathbf{T a S}_{3}$
}

\author{
H. Mutka (*), S. Bouffard, \\ Section d'Etude des Solides Irradiés, Centre d'Etudes Nucléaires, B.P. 6, 92260 Fontenay-aux-Roses, \\ France \\ G. Mihály and L. Mihály \\ Central Research Institute for Physics, 1525 Budapest 114, P.O.B. 49, Hungary
}

(Reçu le 14 octobre 1983, accepté le 19 décembre 1983)

\begin{abstract}
Résumé. - Des expériences de résistance dynamique, de spectre de bruit et de diffraction électronique ont été effectuées pour des températures comprises entre 75 et $280 \mathrm{~K}$ sur du $\mathrm{TaS}_{3}$ orthorhombique irradié. Pour les faibles concentrations en défauts $\left(<10^{-4}\right.$ déplacement par atome de tantale), le champ seuil $\left(E_{\mathrm{T}}\right)$ d'apparition de la conductivité non linéaire augmente linéairement avec la concentration en défauts. Alors que la température de la transition de Peierls $\left(T_{\mathrm{p}}\right)$ n'est pas changée.

Parallèlement les pics étroits apparaissant dans le spectre de bruit s'estompent tandis que le bruit large bande augmente. A plus forte concentration en défauts, $T_{\mathrm{p}}$ décroît et la cohérence transversale des ODC est perdue. Dans ce régime, le seuil bien marqué disparaît des propriétés non linéaires.

Abstract. - Dynamic resistance, noise spectrum and electron diffraction studies on electron irradiated orthorhombic $\mathrm{TaS}_{3}$ were performed in the temperature range of $75 \mathrm{~K}-280 \mathrm{~K}$. At low defect concentrations $\left(<10^{-4}\right.$ displacement per Ta atoms) the threshold field of the nonlinear conductivity $\left(E_{\mathrm{T}}\right)$ increases linearly with the irradiation dose in spite of the fact that there is hardly any effect on the Peierls transition temperature, $T_{\mathrm{p}}=221 \mathrm{~K}$. Concomitantly the sharp peaks in the noise spectrum are smeared out and the broad band noise level increases. At higher defect concentrations, $T_{\mathrm{p}}$ decreases and the transverse coherence of CDWs is lost. In this regime the sharp threshold disappears from the nonlinear characteristics.
\end{abstract}

Several linear chain compounds $\left(\mathrm{NbSe}_{3}, \mathrm{TaS}_{3}, \mathrm{~K}_{0.30} \mathrm{MoO}_{3} \ldots\right)$ [1-3] with charge-density wave (CDW) ground states exhibit a sudden increase of conductivity above a threshold value of the applied electric field, $E_{\mathrm{T}}$. The extra conductivity is explained as being due to the sliding of the CDW condensate [4]. It is generally accepted that impurities and other point defects that pin the CDW have a fundamental influence on the magnitude of $E_{\mathrm{T}}$. Furthermore it has been suggested that the characteristic noise spectrum of the sliding CDW is associated with the pinning of the CDW by defects $[4,5]$. Theoretical works have shown that the pinning centres can be classified as being strong or weak, depending on the stiffness of the CDW and on the strength of the impurity - CDW interaction [6]. The collective effect of pinnings has been discussed recently in the framework of a mean field calculation [7].

(*) Present address : Reactor Laboratory, Technical Research Centre of Finland, 02150 Espoo 15, Finland. 
Different authors investigated the defect dependence of the electrical properties of these materials. Proton irradiation proved to be an effective tool to destroy the lattice but it is difficult to determine the number of defects induced by this way [8]. Introducing a minor amount of $\mathrm{Fe}$ in $\mathrm{NbSe}_{3}$ also leads to significant changes in phenomena associated to CDW motion [9]. Alloying is another method, applied successfully for $\mathrm{TaS}_{3}[10]$.

In order to examine the rôle of lattice disorder we performed measurements on electronirradiated orthorombic $\mathrm{TaS}_{3}$. The CDW transport characteristics of the pure material have been reported in several papers [2]. Fast electron irradiation results in well-controlled and varying defect concentrations starting from the ppm level [11, 12].

Dynamic resistance $(\mathrm{d} V / \mathrm{d} I)$ and noise spectrum were recorded in situ with increasing irradiation doses. A Van de Graaff accelerator provided $2.5 \mathrm{MeV}$ electrons for irradiation. The irradiation and the measurements were carried out in gaseous $\mathrm{H}_{2}$ at temperatures ranging from $75 \mathrm{~K}$ to $280 \mathrm{~K}$. The four probe samples were mounted on a massive holder with good thermal contact. Self heating did not affect the observed nonlinear phenomena. The field dependent dynamic resistance was measured by superimposing an ac excitation $\left(\sim 100 \mathrm{~Hz}, 10^{-2} \times E_{\mathrm{T}}\right)$ on the dc current and using a phase sensitive detection for the ac response. The noise spectra were obtained with a spectrum analyser up to $300 \mathrm{kHz}$, providing the dc current from a battery.

Other samples were separately irradiated under similar conditions and studied with dc pulse measurements for the nonlinearity. Some of them were also examined by electron diffraction in a $100 \mathrm{kV}$ microscope using a liquid nitrogen cooled sample holder.

Under the actual irradiation conditions the most important stable defects produced are the displaced Ta atoms and the vacancies left by them. This argument is based on the observations made on monoclinic $\mathrm{TaS}_{3}$ in an earlier study [11]. The defect production rate depends only on the composition and the local atomic coordination which are similar in monoclinic and orthorhombic $\mathrm{TaS}_{3}$. Accordingly, we can use the displacement threshold energy obtained for monoclinic $\mathrm{TaS}_{3}$ in [11] to calculate the fraction of displaced $\mathrm{Ta}$ atoms (displacements per Ta, dpTa) in the orthorhombic one. We use this number to indicate the irradiation dose and it should be a quite good estimate for the defect concentration.

Another important observation made on monoclinic $\mathrm{TaS}_{3}$ was that the displacement of sulphur atoms does not create defects that are stable at temperatures between 70 and $280 \mathrm{~K}$. This point has not been studied in detail for the orthorhombic polytype but there is no reason to believe that the behaviour is different.

The critical temperature of the CDW transition, $T_{\mathrm{p}}$, was determined from the peak of the numerical derivative of the ohmic $\log R$ vs. 1/T curves. Figure 1 shows the variation of $T_{\mathrm{p}}$ with defect concentration. In our pure and slightly irradiated $\left(10^{-6} \ldots 10^{-5} \mathrm{dpTa}\right)$ samples $T_{\mathrm{p}}^{\mathrm{p}}$ was around $221 \mathrm{~K}$ and the decrease is first observable well above the $10^{-4}$ level. $T_{\mathrm{p}}$ decreases down to $210 \mathrm{~K}$ at a few $10^{-3} \mathrm{dpTa}$. This decrease is accompanied by a considerable smearing of the transition as it can be seen in the $\mathrm{d}(\log R) / \mathrm{d}(1 / T)$ curves in the inset of figure 1 . In addition, electron diffraction results show that at the dose scale $10^{-3} \mathrm{dpTa}$ the CDW loses its transverse coherence. The sharp low temperature satellites broaden gradually and turn into continuous diffuse planes with modulated intensity when approaching $10^{-2} \mathrm{dpTa}$, as illustrated in figure 2 [13].

Variations of the ohmic resistance were observed only near $T_{\mathrm{p}}$ and in the metallic phase above $T_{\mathrm{p}}$. In contrast below $T_{\mathrm{p}}(T<200 \mathrm{~K})$ the irradiation does not change the ohmic resistance at all. Careful investigation of the temperature dependence of the ohmic conductivity demonstrated that the well defined thermal activation energy, consequently, the Peierls gap, remains also unaffected by irradiation induced defects [14].

Apparently, defect concentrations below $10^{-4} \mathrm{dpTa}$ have very little influence on $T_{\mathrm{p}}$ and on the transverse coherence of the CDW. However, in this range of defect concentrations the threshold field of the nonlinear conduction $E_{\mathrm{T}}$ is strongly affected. Figure 3 gives some examples 


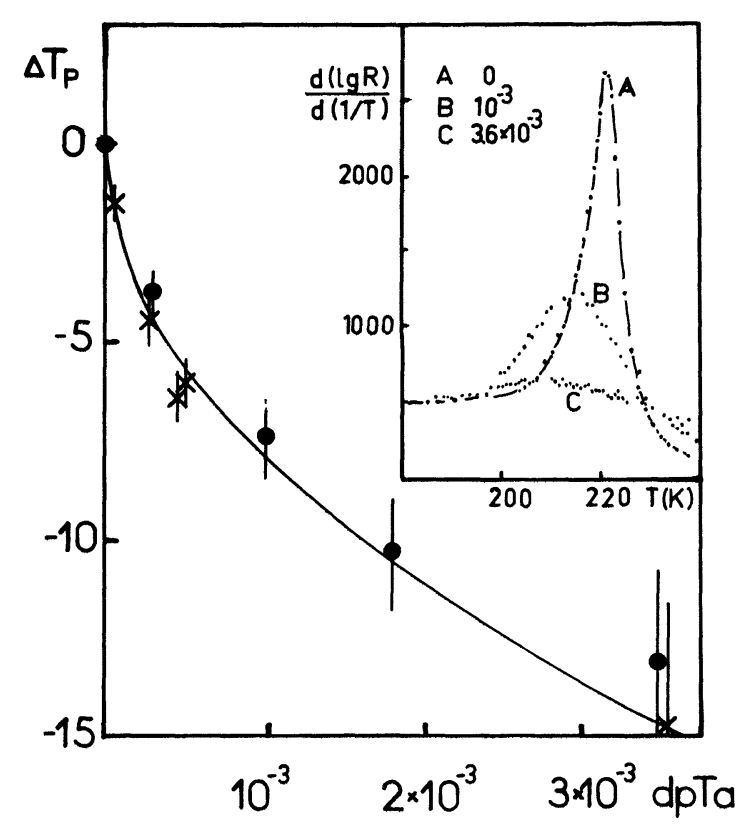

Fig. 1. - The variation of the CDW transition temperature $T_{\mathrm{p}}$ with defect concentration is observed at doses above $10^{-4} \mathrm{dpTa}$ and has a square root dependence on the dose (solid line $\Delta T_{\mathrm{p}}=-250 \sqrt{\mathrm{dpTa}}$ ). The dlog $R / \mathrm{d}(1 / T)$ curves of the inset show how the transition becomes smeared with increasing defect concentration ( $x$ in situ measurements, $\bullet$ contacts made after irradiation).

of the $\mathrm{d} V / \mathrm{d} I$ curves obtained at different concentrations, while in figure 4 we have collected the results from the variation of $E_{\mathrm{T}} v s$. irradiation dose in several samples. A linear, temperature independent increase is observed up to a few $10^{-5} \mathrm{dpTa}$. Then at higher doses the sharp threshold disappears gradually from $\mathrm{d} V / \mathrm{d} I$ curves. In this range the determination of the threshold field is ambiguous. Pulsed dc measurements were used to study the nonlinear characteristics above $10^{-4} \mathrm{dpTa}$. We found a weak increase in $\sigma(E)$ starting at $E_{\mathrm{T}}$ followed by a rapid rise above the field value denoted by $E_{\mathrm{T}}^{*}$. ( $E_{\mathrm{T}}^{*}$ is about 2-3 times $\left.E_{\mathrm{T}}\right)$. The conductivity change between $E_{\mathrm{T}}$ and $E_{\mathrm{T}}^{*}$ is less than $10 \%$. The gradual increase of the conductivity may indicate a smearing of the threshold field or an increased damping of the CDW motion at low velocities. It cannot be excluded however that a static deformation of the CDWs by the electric field decreases the single particle gap and the slight increase in the conductivity between $E_{\mathrm{T}}$ and $E_{\mathrm{T}}^{*}$ originates in the increase of the number of normal electrons. In this case $E_{\mathrm{T}}$ would be the real threshold field. While $E_{\mathrm{T}}^{*}$ follows the linear concentration dependence the increase of $E_{\mathrm{T}}$ with the defect concentration is weaker than linear above $10^{-4} \mathrm{dpTa}$.

The linear dependence of $E_{\mathrm{T}}$ on defect concentration, $c$, has been predicted theoretically in the case of strong pinning [6] when the phase of CDW is rigidly fixed at the defect site. Further evidence for the presence of irradiation induced strong pinnings comes from a comparison with recent results [10] obtained in $\mathrm{TaS}_{3}$ alloyed with $\mathrm{Nb}$ or Se. In these cases the specific influence of defects, $\mathrm{d} E_{\mathrm{T}} / \mathrm{d} c$, is almost two orders of magnitude smaller and $E_{\mathrm{T}}$ was found to be proportional to $c^{2}$, in agreement with theoretical results for weak pinnings [6].

It is interesting to note that in the alloyed samples a considerable decrease of $T_{\mathrm{p}}$ is observed when $E_{\mathrm{T}}$ reaches a few $\mathrm{V} / \mathrm{cm}$ but with irradiation defects with a similar change of $E_{\mathrm{T}}$ the value of $T_{p}$ remains unchanged. We believe that in both cases the decrease of $T_{p}$ is caused by the 

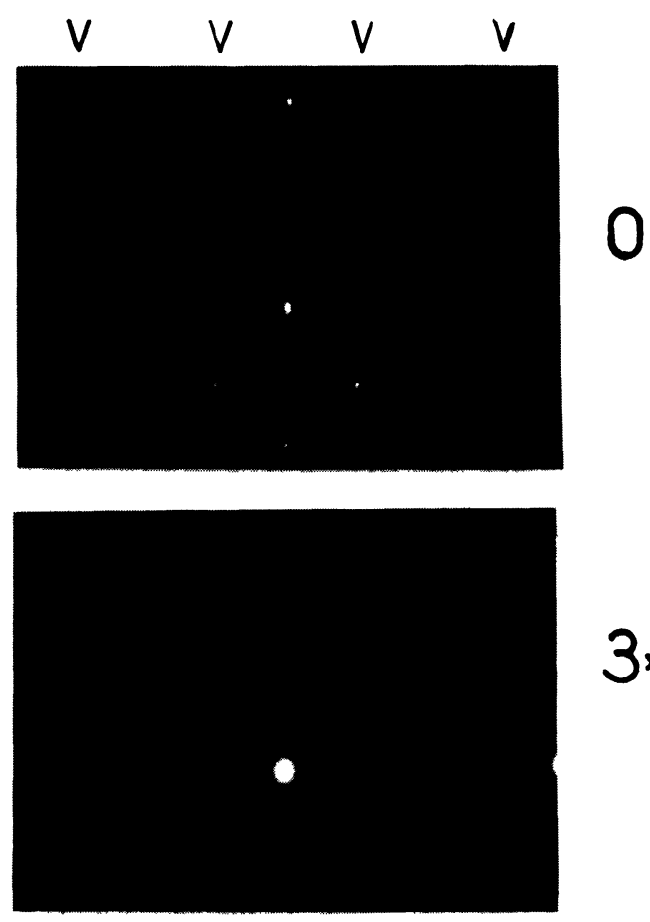

$$
3 \times 10^{-4}
$$
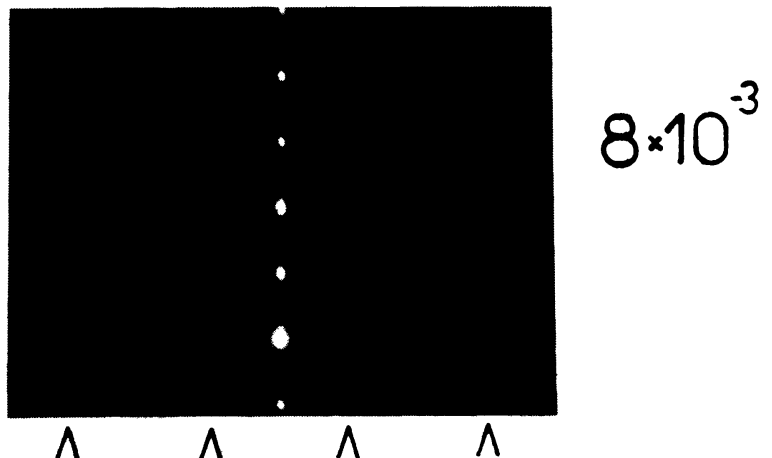

Fig. 2. - Electron diffraction patterns obtained at low temperature (sample holder at $80 \mathrm{~K}$, the sample about 20 degrees warmer) indicate a broadening of the CDW superlattice spots on the dose scale $10^{-3} \mathrm{dpTa}$, due to the loss of the transverse coherence of the CDW distortion. The superlattice spot rows are marked with arrowheads. The intensities of the CDW spots on each pattern are not comparable because of differences in sample orientation.

appearance of significant elastic energy contributions due to static deformation of CDWs. For strong pinning this term seems to be negligible below defect concentrations of $10^{-4} \mathrm{dpTa}$.

Strong variation of the noise spectrum accompanies the linear increase of $E_{\mathrm{T}}$. Figure 5 shows the noise spectra obtained on the same sample at various defect concentrations. Increase of harmonic content, broadening of the periodic peaks and increase of the broad band noise level are observed with increasing defect concentrătion. Recordings of noise spectra at different values of the dc current indicated that defects do not affect the dependence of the fundamental periodic frequency on the excess current. These preliminary results suggest that disregarding the physical 


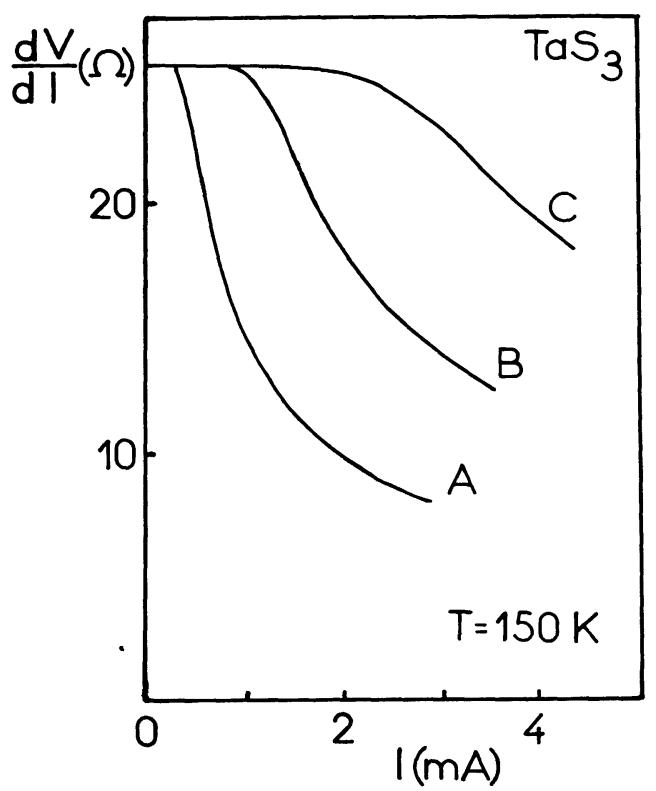

Fig. 3. - Dynamic resistance curves for a single sample at $150 \mathrm{~K}$ for various defect concentrations. A : non irradiated, $B: 3.2 \times 10^{-5} \mathrm{dpTa}, \mathrm{C}: 9.7 \times 10^{-5} \mathrm{dpTa}$. On curve $\mathrm{C}$ the very sharp threshold typical of pure samples begins to disappear.

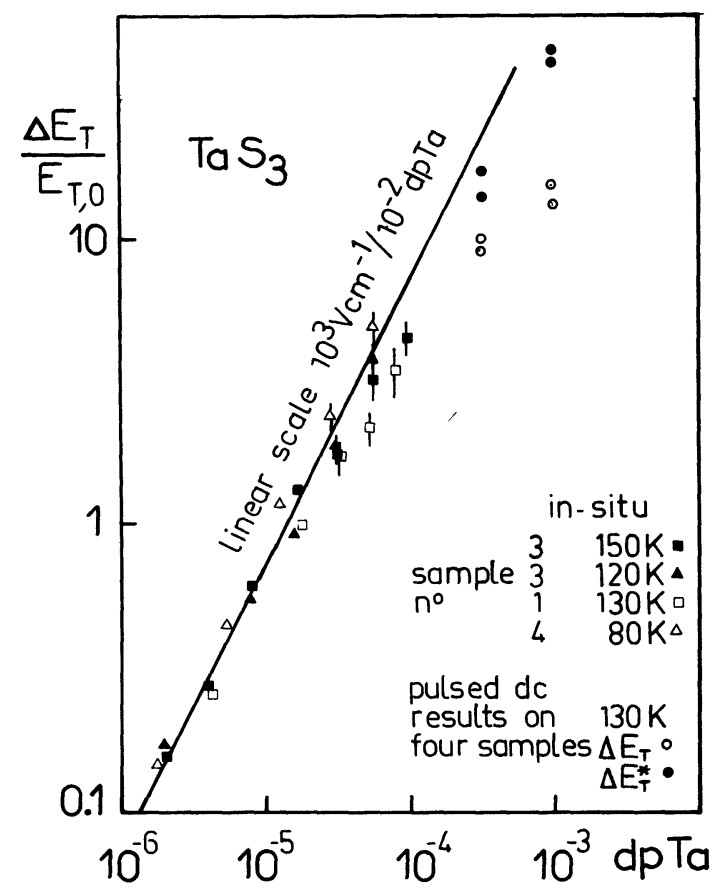

Fig. 4. - Collected data for the variation of $E_{\mathrm{T}}$ with irradiation dose. We plot the change $\Delta E_{\mathrm{T}}$ normalized to the initial value $E_{\mathrm{T}, 0}$ in order to suppress any inaccuracy in the sample length measurement. For the crystals used in this study $E_{\mathrm{T}, 0} \simeq 1 \mathrm{~V} / \mathrm{cm}$ between 80 and $150 \mathrm{~K}$. The error bars of the in situ measurements are due to the smearing of the sharp threshold of $\mathrm{d} V / \mathrm{d} T$ curves. The experimental points below $10^{-4} \mathrm{dpTa}$ follow closely the straight line representing a linear variation with a slope of $1000 \mathrm{~V} \mathrm{~cm}-1 / 10^{-2}$ $\mathrm{dpTa}$. Above $10^{-4} \mathrm{dpTa}$ we determined two characteristic fields from dc pulse measurements : $\Delta E_{\mathrm{T}}(\mathrm{O})$ where slight nonlinear conductivity set in and $\Delta E_{\mathrm{T}}^{*}(\bullet)$ above which the rapid rise was observed in $\sigma(E)$. 


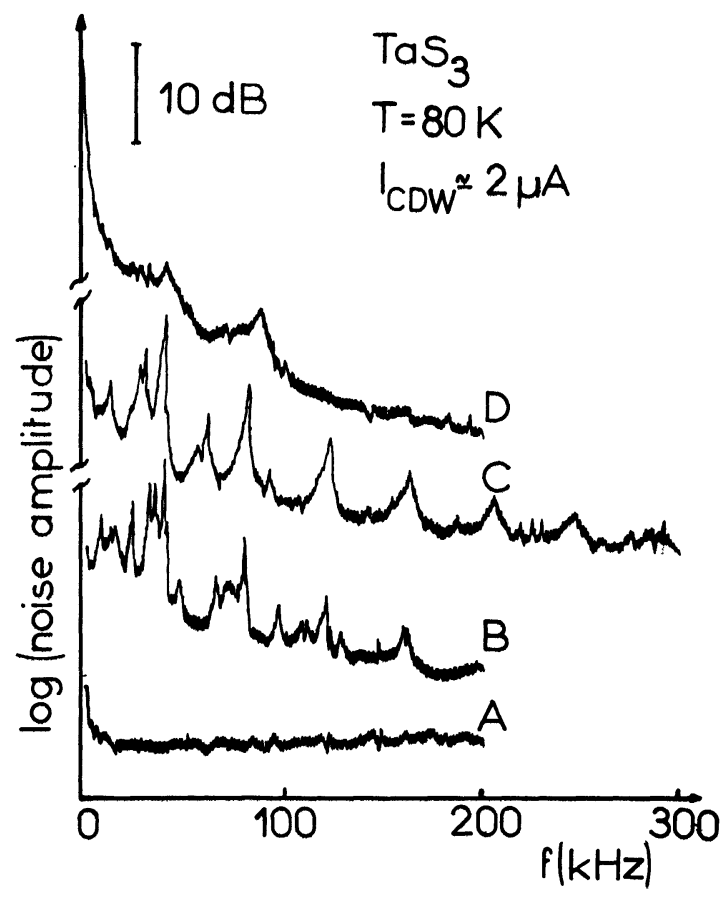

Fig. 5. - The noise spectra observed in situ at various defect concentrations. A : the background noise for $E<E_{\mathrm{T}}$, B : before irradiation, $\mathrm{C}: 7 \times 10^{-6} \mathrm{dpTa}$, displaced $15 \mathrm{~dB}$ upwards for clarity. Note the strengthening of the higher harmonics, more than 10 of them were observed with $I_{\mathrm{CDw}} \simeq 1 \mu \mathrm{A}, \mathrm{D}: 6 \times 10^{-5} \mathrm{dpTa}$, displaced $25 \mathrm{~dB}$ upwards for clarity. There is a considerable increase of the broad band noise below $100 \mathrm{kHz}$.

origin of the noise (sliding of the CDW in a defect induced periodic potential $[4,5,15]$ vortices at contacts [16], deformations of the CDW [17] for example), the explanation of the noise phenomena has to take into account the strong variation of the noise amplitude with defect concentration.

In conclusion we have demonstrated that at the extreme low defect concentrations, available using electron irradiation, the threshold field is proportional to the defect concentration. The large increase of $E_{\mathrm{T}}$ at low concentrations together with the linear concentration dependence suggest that this kind of defects acts as strong pinnings. Variations in the noise spectrum also indicate their important rôle in the depinning process. However, the electron diffraction pattern, which characterizes the coherence of CDWs and the transition temperature $T_{\mathrm{p}}$, is not affected in this range. On the other hand, at higher concentrations, when the coherence of CDWs begins to break down, the sharp threshold disappears from the nonlinear characteristics, the phase transition is smeared out and the transition temperature decreases.

Electron irradiation has proved to be a reliable and well controlled method for introducing strong pinning centres into $\mathrm{TaS}_{3}$. Further studies on the nature of the noise spectrum and on the metastable states are in progress on irradiated samples. 


\section{References}

[1] Monceau, P., Richard, J. and Renard, M., Phys. Rev. B 25 (1982) 931.

[2] Zettl, A., Grüner, G. and Thompson, A. H., Phys. Rev. B 26 (1982) 5760.

Zettl, A., JACKSON, C. M. and GrüNER, G., Phys. Rev. B 26 (1982) 5773.

[3] Dumas, J., Schlenker, C., Marcus, J. and Buder, R., Phys. Rev. Lett. 50 (1983) 757.

[4] Grüner, G., Commun. Solid State Phys. 10 (1983) 183.

[5] Grüner, G., Zawadowski, A., Chaikin, P. M., Phys. Rev. Lett. 46 (1981) 511.

[6] Lee, P. A. and RICE, T. M., Phys. Rev. B 19 (1979) 3970 ;

Fukuyama, H. and Lee, P. A., Phys. Rev. B 17 (1978) 476.

[7] Fisher, D. S., Phys. Rev. Lett. 50 (1983) 1486.

[8] Chaikin, P. M., Fuller, W. W., Lacöe, R., Kwak, J. F., Green, R. L., Eckert, J. C. and Ong, N. P., Solid State Commun. 39 (1981) 553.

[9] Everson, M.P. and Coleman, R. V., preprint.

[10] Pei-Ling Hsieh, de Czito, F., Jánossy, A. and Grüner, G., Proc. of the International Colloque of C.N.R.S., Les Arcs 1982 published in J. Physique Colloq. 44 (1983) C3-1753.

[11] Mihály, G., Housseau, N., Mutka, H., Zuppiroli, L., Pelissier, J., Gressier, P., Meerschaut, A. and RouXel, J., J. Physique Lett. 42 (1981) L-263.

Lesueur, D., Morillo, J., Mutka, H., Andouard, A. and Jousset, J. C., Rad. Effects 77 (1983) 125.

[12] Monceau, P., Richard, J. and LAgnier, R., J. Phys. C 14 (1981) 2995.

[13] Similar observations were reported on monoclinic $\mathrm{TaS}_{3}$ in [11].

[14] Mihály, G., Mihály, L. and MutKa, H., to be published.

[15] Klemm, R. A. and Schrieffer, J. R., Phys. Rev. Letters 51 (1983) 47.

[16] ONG, N. P., Verma, G. and MAKI, K., preprint.

[17] GiLl, J. C. and HigGs, A. W., preprint. 